\title{
REVIEW
}

\section{Extreme Catalysts from Low-Temperature Environments}

\author{
ANNE HOYOUX,,${ }^{1}$ VINCIANE BLAISE,${ }^{1}$ TONY COLLINS,${ }^{1}$ SALVINO D'AMICO, ${ }^{1}$ \\ EMMANELLE GRATIA, ${ }^{1}$ ADRIENNE LOUISE HUSTON,${ }^{1}$ JEAN-CLAUDE MARX, ${ }^{1}$ \\ GUILLAUME SONAN, ${ }^{1}$ YINXIN ZENG,${ }^{1}$ GEORGES FELLER, ${ }^{1}$ \\ AND CHARLES GERDAY ${ }^{*}$
}

Laboratory of Biochemistry, Institute of Chemistry B6, University of Liège, Sart-Tilman, Liege B-4000, Belgium

Received 26 July 2004/Accepted 23 August 2004

\begin{abstract}
Cold-loving or psychrophilic organisms are widely distributed in nature as a large part of the earth's surface is at temperatures around $0^{\circ} \mathrm{C}$. To maintain metabolic rates and to prosper in cold environments, these extremophilic organisms have developed a vast array of adaptations. One main adaptive strategy developed in order to cope with the reduction of chemical reaction rates induced by low temperatures is the synthesis of cold-adapted or psychrophilic enzymes. These enzymes are characterized by a high catalytic activity at low temperatures associated with a low thermal stability. A study of protein adaptation strategies suggests that the high activity of psychrophilic enzymes could be achieved by the destabilization of the active site, allowing the catalytic center to be more flexible at low temperatures, whereas other protein regions may be destabilized or as rigid as their mesophilic counterparts. Due to these particular properties, psychrophilic enzymes offer a high potential not only for fundamental research but also for biotechnological applications.
\end{abstract}

[Key words: psychrophile, extremophiles, cold adaptation, enzyme kinetics, flexibility strategy]

Life under low-temperature conditions was identified as early as 1840 by Hooker, who observed that algae were associated with sea ice. In 1887, Forster was the first who reported that microorganisms isolated from fish could grow well at $0^{\circ} \mathrm{C}(1)$. The term "psychrophilic" was first used in 1902 by Schmidt-Nielsen to describe such cold-adapted organisms (2). Psychrophile is defined as an organism, prokaryotic or eukaryotic, living permanently at temperatures close to the freezing point of water in thermal equilibrium with the medium. Thus psychrophiles are numerous, including a large range of species of gram-positive and gram-negative bacteria, yeast, algae, marine invertebrates, insects and polar fish, and are widely distributed (3). Psychrophiles have developed mechanisms of adaptation to temperature including a huge range of structural and physiological adjustments in order to cope with the deleterious effect of low temperatures. Indeed, they display metabolic fluxes at low temperatures that are more or less comparable to those exhibited by closely related mesophiles living at moderate temperatures (4-6). This is explained by the capability of these psychrophilic organisms to produce "cold-adapted" enzymes which are able to cope with the reduction of chemical reaction rates induced by low temperatures. However, most cellular adaptations to low temperatures and the underlying molecu-

\footnotetext{
* Corresponding author. e-mail: ch.gerday@ulg.ac.be
} phone: +32-4-3663340 fax: +32-4-3663364 lar mechanisms are not fully understood and are still being investigated. Moreover, a study of proteins and enzymes from cold-adapted organisms is not only useful in the understanding of some general processes related to the protein structure and function but also in protein folding investigations. In addition, cold-active and heat-labile psychrophilic enzymes possess an interesting biotechnological potential.

\section{PSYCHROPHILIC ORGANISMS}

Cold-adapted organisms prosper at temperatures close to the freezing point of water and have successfully colonized permanently cold habitats such as polar and alpine regions or deep-sea waters (7-9). These cold habitats constitute more than three-quarters of the earth's surface and are exposed to temperatures that are more or less permanently below $5^{\circ} \mathrm{C}$. Microbial growth and metabolic activities have been recorded beneath 3-6 $\mathrm{m}$ of ice in permanently frozen lakes, in subglacial ice and sediments, in surface snow at the South Pole where the highest summer temperatures remain well below zero (at least $-10^{\circ} \mathrm{C}$ ). Moreover, biological activities have been recorded in the brine veins of sea ice at temperatures as low as $-20^{\circ} \mathrm{C}(10)$. More often, psychrophilic microorganisms are not only adapted to low temperatures but also to other environmental constraints. In deepsea water, for example, they have to be adapted to extremely high pressure and therefore must be, at the same time, psy- 
chrophiles and piezophiles (11). Temperature is one of the most important environmental factors for life, as it influences most biochemical reactions. In order to overcome the detrimental effect of low temperatures, psychrophiles have developed various adaptive strategies. One of the strategies used in order to withstand temperatures below freezing is the protection of the cells from ice formation by the synthesis of antifreeze molecules and cryoprotectors (12). Another problem is the decrease in membrane fluidity with temperature. Indeed, major cellular functions, including passive and active permeabilities, nutrient uptake, electron transport, environmental sensing, photosynthesis, and recognition processes, require the maintenance of membrane fluidity. The membrane of microorganisms contains a lipid bilayer that must have the proper fluidity to support most biological functions. As temperature is decreased, fatty acid side chains in membrane bilayers undergo a change of state from a disordered liquid crystalline state to a gel-like state (13). To maintain the membrane stability, psychrophilic microorganisms increase the ratio of unsaturated to saturated fatty acids and modulate the activities of the enzymes involved in fatty acid and lipid biosyntheses (3).

Sudden decreases in temperature will elicit a specific alteration in gene expression known as the cold-shock response, which is distinct from the general stress response (heat shock) in terms of both the nature of the proteins induced and regulatory aspects (3). The cold-shock response involves the induction and the synthesis of cold-shock proteins. The regulation of cold-shock protein synthesis is multifactorial, being controlled at the levels of both transcription and translation, as well as mRNA and protein stabilities. The main functions of cold-shock proteins (Csp) are in the regulation of cellular protein synthesis, at the level of transcription as well as the initiation of translation, and in mRNA folding, acting as a chaperone preventing the formation of an mRNA secondary structure (14). However, in psychrophilic microorganisms, the synthesis of housekeeping gene products is not inhibited by cold shock, and the number of cold-shock proteins is usually higher and increases with the severity of the cold shock. In contrast, in these microorganisms, one set of proteins, known as coldacclimation proteins (CAPs), is permanently induced by continuous growth at low temperatures (15). One acclimation protein is known to be analogous to $\mathrm{CspA}$, a major cold-shock protein in Escherichia coli (16) but the cellular functions of acclimation proteins remain not well understood. Low temperatures promote unfavourable RNA secondary structures, which are likely to interfere with translation, and strengthen the interactions between DNA strands in the double helix and in the supercoiled state, therefore impairing unwinding and access to RNA polymerase. Nucleic-acid-binding proteins relieve the adverse effects of low temperatures and could play a central role in the cold adaptation of psychrophiles $(17,18)$. Other adaptive strategies developed by psychrophilic organisms involve the regulation of ion channel permeability, seasonal dormancy and microtubule polymerization (19-21). In addition to these cellular adaptations, a key adaptive strategy of psychrophiles is the modification of enzyme kinetics, allowing the emergence of metabolic rates compatible to life at low temperatures. In- deed, low temperatures strongly inhibit the rate of chemical reactions. The temperature dependence of chemical reactions is described by the Arrhenius equation $k=\mathrm{Ae}^{-E_{d} / R T}$, in which $A$ is the pre-exponential factor (related to steric factors and molecular collision frequency), $E_{\mathrm{a}}$ is the activation energy, $R$ is the gas constant $\left(8.314 \mathrm{JK}^{-1} \mathrm{~mol}^{-1}\right)$ and $T$ is the absolute temperature in Kelvin. Thus, any decrease in temperature will induce an exponential decrease in the reaction rate and for most biological systems, a decrease of $10^{\circ} \mathrm{C}$ depresses the rate of chemical reactions by a factor ranging from 2 to 3 corresponding to $Q_{10}$ (which expresses the ratio of reaction rates measured at an interval of temperature of $10^{\circ} \mathrm{C}$ ). Nevertheless, psychrophiles succeed to maintain an appropriate rate for enzyme-catalyzed reactions that are involved in essential cellular processes by synthesizing coldactive, but heat-labile, enzymes with an activity that is up to 10 times higher at low temperatures than that of their mesophilic homologues. The synthesis of such cold-active or psychrophilic enzymes is the main physiological adaptation at the enzyme level.

\section{PSYCHROPHILIC ENZYMES}

\section{Structural factors involved in the stability and the} activity of psychrophilic enzymes

Structural adaptations related to stability The attenuation in strength and number of structural factors known to stabilize proteins could be involved in the low stability of psychrophilic enzymes $(6,22,23)$. One mutational study has shown that the accumulation of several mutations, which stabilize weak interactions in the psychrophilic $\alpha$-amylase, resulted in a strongly stabilized mutant displaying kinetic parameters close to those of the mesophilic homologue (24, $25)$. In the $\alpha$-amylase, the lower stability of the psychrophilic enzyme originates from a general weakening of intramolecular forces which contribute to the stability of the native protein molecule. In this case, the overall decrease in the thermostability of the cold-adapted protein provides a sufficient plasticity around the catalytic residues to render the enzyme efficient at low temperatures. The decrease in global stability has been observed in particular for psychrophilic enzymes which operate on large substrates such as $\alpha$-amylases and proteases. The lower stability of cold-active enzymes could also originate from weakened interactions in one or a few regions of the structure. Localized flexibility has been demonstrated by microcalorimetric studies of multidomain proteins (26-28). In psychrophilic chitobiase and the $\alpha$-amylase precursor, differences in stability can be found between regions carrying the active site and the other moieties of the protein: The active site is embedded in a heatlabile domain, whereas the stability of other domains is unaffected or even enhanced. In psychrophilic phosphoglycerate kinase, the two domains are connected by a hinge region that bends during catalysis forming the active site at the interface of both the heat-labile and heat-stable domains. The heat-labile domain could provide the required flexibility around the active site and favour the reaction rate, whereas the heat-stable domain, having the same stability as that of the mesophilic enzyme, could improve substrate binding as a result of its rigidity and appropriate comple- 
mentarities with the substrate (28).

Each protein uses one or a combination of possible structural adjustments to reduce the local or global stability of the molecular edifice. In addition to mutational studies, the involvement of these factors in protein adaptation is suggested from comparative studies between psychrophilic enzymes and their heat-stable homologues based on homology models and 3D structures. An increased number of crystallographic structures of psychrophilic enzymes from bacteria and cold-adapted fishes have been previously elucidated (29-41). Among these structures, seven have been compared with mesophilic or thermophilic homologues. These include the bacterial xylanase (31), $\alpha$-amylase (42), citrate synthase (32), malate dehydrogenase (35), alkaline $\mathrm{Ca}^{2+}-\mathrm{Zn}^{2+}$ protease (30), triose-phosphate isomerase (34), insect lysozyme (41), fish uracil-DNA glycosylase (29) and fish trypsin (37). Other structures should become available soon, as crystals of three other cold-active enzymes have been obtained (43-45).

Compared to their mesophilic and thermophilic counterparts, structural modifications found in psychrophilic enzymes involve the clustering of glycine residues (providing local mobility), a decrease in the number of proline residues in loops (providing enhanced chain flexibility between secondary structures), a decrease in the number of arginine residues which are capable of forming multiple salt bridges and hydrogen bonds, as well as a lower number of ion pairs, aromatic interactions or hydrogen bonds, and the weakening of charge-dipole interactions in $\alpha$-helices. Nonpolar core clusters can have a weaker hydrophobicity, making the protein interior less compact, the binding of stabilizing cofactors such as metal ions can be weaker and loose protein extremities appear to be preferential sites for unzipping. However, a few common trends in the structural strategies used in the adaptation to temperatures are observed: a decrease in the number of ionic interactions in psychrophilic enzymes compared to their mesophilic and thermophilic homologues, a decrease in the fraction of accessible surface of side chains and a reduced apolar fraction of the buried surface with decreasing apparent optimal temperature (23).

Comparisons of some psychrophilic enzymes with their mesophilic and thermophilic homologues showed not only that each cold-adapted enzyme adopts its own adaptive strategy but also that there is a continuum in the strategy of protein adaptation to temperatures as illustrated below. In the dimeric citrate synthase, as one ascends the temperature ladder, the subunit interface of this enzyme and loop regions are reinforced by complex electrostatic interactions, and there is a reduced exposure of the hydrophobic surface. There is a progressive pattern of stabilization through multiple additional interactions at solvent-exposed, loop and interfacial regions (46). A comparison of the structure of Pseudoalteromonas haloplanktis xylanase with that of thermophilic endoglucanase Cel A from Clostridium thermocellum suggested that cold adaptation is achieved by a decrease in the number of salt bridges and an increased exposure of hydrophobic residues (31). Compared to its mesophilic and thermophilic homologues AKsub and AKste, the psychrophilic adenylate kinase Akglo has the most apolar exposed surface area, although it has the fewest apolar atoms. A strong correlation is found between the thermal stability and apolar buried surface area of the adenylate kinases (47). The determination of the composition of the accessible surface of DNA ligases Phlig, Eclig and Tslig showed a decrease in charged surface in the order thermophile to psychrophile (48). Such a decrease could lead to a decrease in the strength of the ion pair network at the surface of the psychrophilic ligase compared to its thermophilic homologue and could improve the resilience of the external shell of the cold-active enzyme.

Structural adaptations related to activity Psychrophilic enzymes are characterized by destabilizing structural adjustments but also by adaptations in their active site. Frequently, their catalytic site reveals an increased size and a better accessibility to ligands when compared to their mesophilic or thermophilic homologues $(22,30,32)$. This is achieved in various ways such as by the deletion of loops bordering the active site, by the distinct conformation of these loops and by the replacement of bulky side chains by smaller groups at the entrance of the active site. This adaptation could allow the accommodation of the substrate at low energy cost and facilitate the release and exit of the reaction products. Nevertheless, the opposite situation can be observed: In psychrophilic xylanase pXyl, the accessibility of the substrate-binding region is substantially lower than that in the thermophilic homologue, which is mainly the result of a loop folding over the groove in pXyl (31). Although all reactive side chains as well as most side chains pointing towards the catalytic activity are strictly conserved in psychrophilic enzymes compared with their mesophilic and thermophilic homologues, changes occurring elsewhere in the molecule can be responsible for the optimization of the catalytic parameters of these enzymes as shown for the psychrophilic $\alpha$-amylase $(24,49)$. Electrostatic potential in and around the catalytic site can be improved so that it may facilitate the interaction of the oppositely charged ligands with the surface of the enzyme $(29,31,32,35,38)$. However, in psychrophilic DNA ligase Phlig, the adenylation domain contains a lower number of charged residues than that of the thermophilic enzyme $T$ slig. This is in agreement with the fact that $k_{\text {cat }}$ is believed to be the most important adaptative parameter for Phlig, while for the DNA ligase $T s$ lig, the adaptative parameter is expected to be $K_{\mathrm{m}}$ for nicked DNA, which is prone to melting at high temperatures. The adenylation domain of the psychrophilic enzyme is destabilized by an excess of hydrophobic surface residues (48). The flexibility of specific residues in the substrate-binding site also seems to be a cold-adapted feature $(30,31,35)$. In the psychrophilic xylanase $\mathrm{pXyl}$, two aromatic residues lining the subsites +1 and +2 were shown to adopt a double conformation. The increased flexibility of these residues may assist the accommodation of the substrate (31). In the psychrophilic cellulase Cel5G, structural adaptation to cellulose hydrolysis at low temperatures is observed in the unusually long linker and in the extended shape of the entire molecule compared with that of the mesophilic Cel45 from Humicola insolens. The unusually long linker of $\mathrm{Cel} 5 \mathrm{G}$ can provide a significant steric optimization of the cellulolytic activity by increasing substrate accessibility (Sonan, G., personal communication). 
Oligomeric enzymes Intersubunit interaction seems to be a major stabilization mechanism of hyperthermophilic oligomeric proteins. The hydrophobic core and ion-pair network at the subunit interface are the major stabilizing factors which stabilize the intersubunit interface (50). Moreover, oligomerization can be a significant stabilization mechanism for hyperthermophilic enzymes (50-53). On the basis of stability studies of dimeric globular proteins, it was calculated that quaternary interactions could provide $25 \%$ to $100 \%$ of the conformational stability in protein dimers (54).

A comparison of the E. coli 3-isopropylmalate dehydrogenase with the Thermus thermophilus enzyme showed a more hydrophobic subunit interface for the thermophilic protein (55). These hydrophobic interactions seemed to make the dimer more resistant to dissociation (56). Similarly, a comparison of the psychrophilic triosephosphate isomerase from Moraxella sp. TA137 and of the thermophilic TIM from Bacillus stearothermophilus with the enzyme from yeast shows three more hydrophobic residues in the $B$. stearothermophilus TIM which enhances the stability of its dimers (57). The alignment of the amino acid sequences of Moraxella sp. TA137 and B. stearothermophilus with respect to that of chicken, the 3D structure of which was already known, showed two small insertions in the loops taking part in the monomer-monomer interface of the dimeric psychrophilic enzyme. These insertions may increase the flexibility of the loops and thereby could lead to the destabilization of the dimer due to a greater loss of entropy upon dimer formation (57).

A comparison of the dimeric cold-active citrate synthase from the antarctic bacterium Arthrobacter DS2-3R with the homologous enzyme from the hyperthermophilic Pyrococcus furiosus shows a decrease in the number of subunit interactions, without any intersubunit ion-pair network in the cold enzyme. This difference and the presence of isoleucine and tyrosine clusters at the interface of the enzyme from $P$. furiosus may account for the difference in thermal stability of each enzyme (32). In the hyperthermophilic citrate synthase, salt bridges organized in networks are largely clustered in the active-site region and at the dimer interface. In the case of the enzyme from $P$. furiosus, electrostatic interactions may contribute to the integrity of both the protein dimer and the active site by possibly reducing conformation disorder at high temperatures. In contrast, in the psychrophilic enzyme, electrostatic interactions are more dispersed throughout the structure and the psychrophilic enzyme contains a greater number of charged residues with large destabilizing electrostatic free-energy contributions. The activesite charged residues of the psychrophilic enzyme show a greater extent of destabilization than those of the thermophilic enzyme and its charged residues on its surface may form favorable electrostatic interactions with the surrounding water molecules along with those among the charged residues themselves. Therefore, in the psychrophilic citrate synthase at low temperatures, electrostatics may contribute to enhance protein solvation and to ensure active-site flexibility (58).

A comparison of the modelized structure of the tetrameric psychrophilic $\beta$-galactosidase from $P$. haloplanktis (59) with the structure of its homologous mesophilic en- zyme from $E$. coli (60) showed the disappearance of two ion pairs, as well as one hydrophobic cluster of 14 residues, at the level of the long interface of the cold-active enzyme, which is responsible for the formation of dimers. At the level of the activating interface, which induces the formation of tetramers and is responsible for the activity, the number of hydrogen bonds is decreased by a factor of five and one hydrophobic cluster is also deleted. This reduced number of stabilizing subunit interactions in the psychrophilic enzyme could be responsible for the decrease in its stability.

Kinetic optimization and heat-labile activity of coldactive enzymes The main physiological adaptation to cold of psychrophilic enzymes is a high activity $\left(k_{\text {cat }}\right)$ at low temperatures which can be 10 times higher than that of their mesophilic homologues. Psychrophilic enzymes succeed to reduce the deleterious effect of low temperatures on enzyme reaction rates by reducing the temperature dependence of their specific activity $\left(k_{\text {cat }}\right)$ which correlates with a decrease in the activation energy of chemical reactions. The catalytic constant $k_{\text {cat }}$ or turnover number corresponds to the maximum number of substrate molecules converted to product per active site per unit of time. In the Michaelis-Menten equation, the catalytic constant $k_{\text {cat }}$ is the first-order rate constant for the chemical conversion of enzyme-substrate complex ES to enzyme and product. The following equation is equivalent to the Arrhenius law and describes the effect of temperature on enzyme activity:

$$
k_{\text {cat }}=\kappa \frac{k_{\mathrm{B}} T}{h} \mathrm{e}^{-\Delta \mathrm{G} \# \mathrm{RT}}
$$

where $k_{\text {cat }}$ is the turnover number, $\kappa$ is the transmission coefficient, $k_{\mathrm{B}}$ is the Bolzmann constant $\left(1.3805 \times 10^{-23} \mathrm{~J} . \mathrm{K}^{-1}\right)$, $h$ is the Planck constant $\left(6.6256 \times 10^{-34} \mathrm{~J}\right.$. s. $), R$ is the gas constant, $\Delta G^{\#}$ is the free energy of activation and $T$ is the absolute temperature. The free energy of activation $\Delta G^{\#}$ is the variation of the Gibbs energy between the activated enzyme-substrate complex ES ${ }^{\#}$ and the ground-state ES according to the transition state theory which assumes the existence of an activated complex $\mathrm{ES}^{\#}$ in equilibrium with the ground-state ES:

$$
\mathrm{E}+\mathrm{S} \leftrightarrow \mathrm{ES} \leftrightarrow \mathrm{ES}^{\#} \rightarrow \mathrm{E}+\mathrm{P}
$$

The thermodynamic parameters of the reaction $\left(\Delta G^{\#}, \Delta H^{\#}\right.$, $\left.\Delta S^{\#}\right)$ can be calculated as described by Lonhienne et al. (61). However, the activated state $\mathrm{ES}^{\#}$ does not really exist as the reagents only flow around this state and an ensemble of a multitude of activated conformations should be possibly considered. Moreover, the transition state theory contains several well-known simplifications and the real and absolute significance of the thermodynamic parameters has to be taken with caution (61). Particularly, the transmission coefficient $\kappa$ is generally considered to be close to one and is, in general, ignored. However, as the viscosity of solvents markedly changes with temperatures, the frictional forces cannot always be neglected especially at low temperatures and should be taken into account according to the Kramers theory (62). Nevertheless, the errors inherent to the transition state theory have been attenuated by the analysis of the variation of the thermodynamic parameters obtained for psychrophilic enzymes with the variation of those obtained 


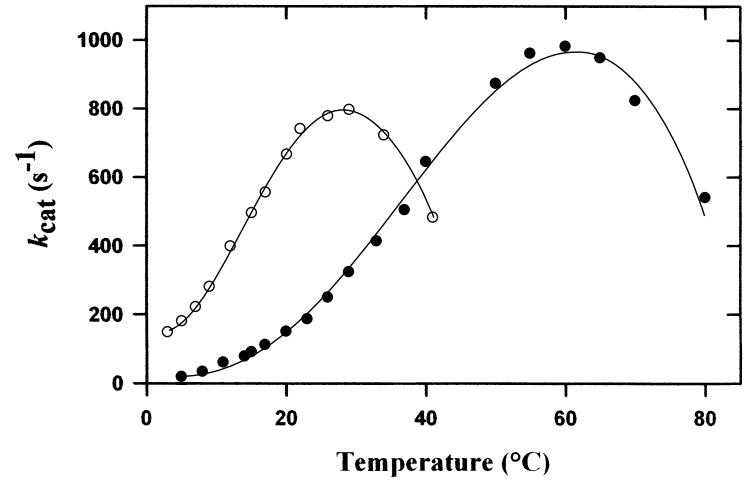

FIG. 1. Effect of temperature on the activity of psychrophilic (open circles) and mesophilic (closed circles) enzymes. Curves representing the thermal dependence of the specific activity of the psychrophilic $\alpha$-amylase from $P$. haloplanktis AHA (open circles) and of its thermostable homologue from B. amyloliquefaciens BAA (closed circles). Adapted from Ref. 106.

for mesophilic enzymes: $\Delta\left(\Delta G^{\sharp}\right)_{\mathrm{p}-\mathrm{m}}, \Delta\left(\Delta H^{\sharp}\right)_{\mathrm{p}-\mathrm{m}}$, and $\Delta\left(\Delta S^{\sharp}\right)_{\mathrm{p}-\mathrm{m}}$ (61). The comparative studies show that psychrophilic enzymes are characterized by lower $\Delta G^{\#}$ values, compared to their mesophilic homologues. As expected, $\Delta\left(\Delta G^{\#}\right)_{\mathrm{p}-\mathrm{m}}$ is negative and its small value originates from large differences in the enthalpic $\Delta\left(\Delta H^{\#}\right)_{\mathrm{p}-\mathrm{m}}$ and entropic contributions $\Delta\left(\Delta S^{\#}\right)_{\mathrm{p}-\mathrm{m}}$ between psychrophilic and mesophilic enzymes (61). The decrease of the activation enthalpy $\Delta H^{\#}$ corresponds to the lower activation energy of the reaction and indicates a reduced temperature dependence of $k_{\text {cat }}$. The low activation enthalpy $\Delta H^{\#}$ is the main adaptive parameter to low temperatures in a reaction catalyzed by psychrophilic enzymes and is achieved structurally by a reduced number of enthalpy-driven interactions that have to be broken to reach the transition state (63). Thus the enzyme regions that are involved in the conformational changes occurring during the catalytic reaction can provide sufficient flexibility to increase $k_{\text {cat }}$ but should be less stable than that of mesophilic enzymes. Consequently, the activity of psychrophilic enzymes is heat-labile and this characteristic is generally well illustrated by the curves representing the thermal dependence of the specific activities of the cold-active enzymes and their heat-stable homologues (Fig. 1). Indeed, these curves show that the apparent maximal activity of cold-active enzymes is shifted towards low temperatures, suggesting a low stability of these enzymes. Interestingly, recent experiments have shown that psychrophilic enzymes are inactivated at temperatures well below that at which the protein unfolds (Fig. 2). This is not the case for their mesophilic and thermophilic homologues which show a temperature of maximal activity corresponding, in general, to the unfolding transition, suggesting that the observed loss of activity is due to protein unfolding $(48,64,65)$. These results confirm the concept of "localized flexibility", suggesting that the high activity at low temperatures is determined by a low stability at or near the active site of psychrophilic enzymes associated or not with a decrease in stability in the regions not involved in the catalysis. The entropic contribution $\Delta\left(\Delta S^{\#}\right)_{\mathrm{p}-\mathrm{m}}$ is always negative and could be a consequence of the active-site flexibility. Indeed, the ground-state enzyme-substrate complex ES occupies a broader distribu-
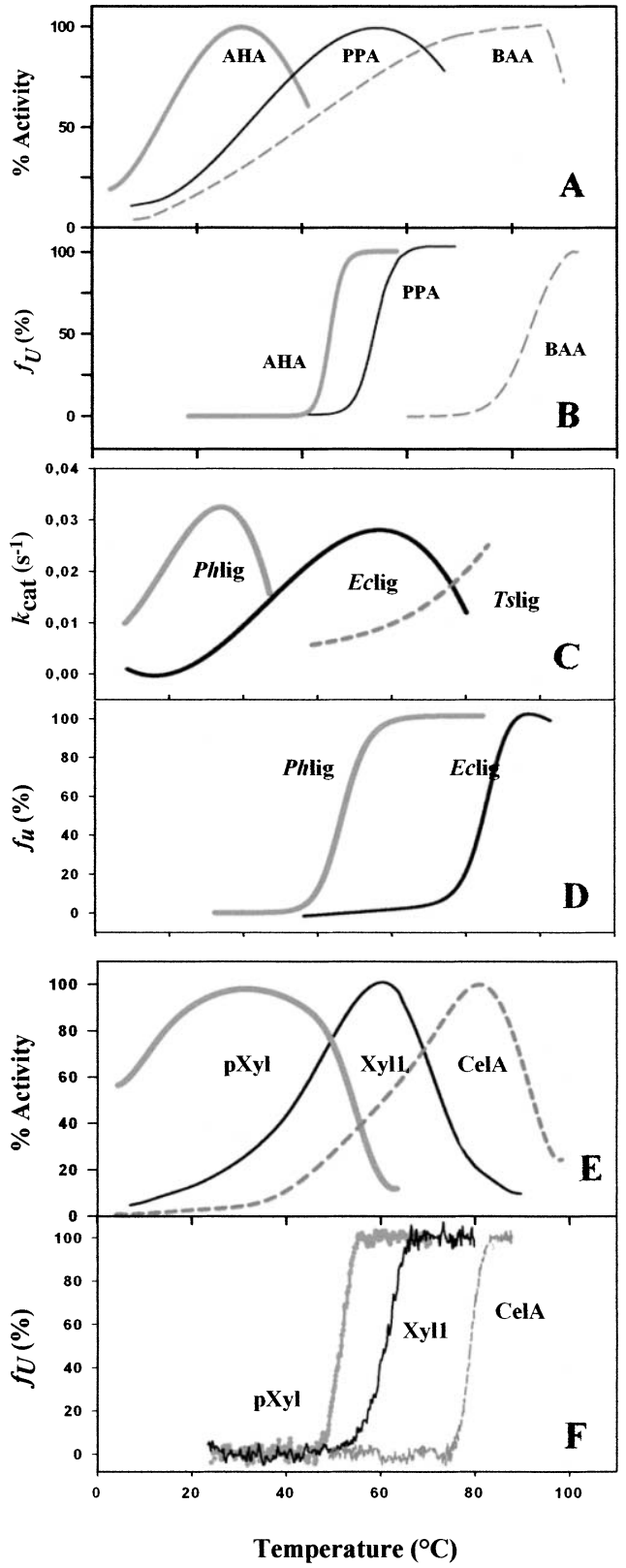

FIG. 2. Temperature dependence of activity (\% activity or $\left.k_{\mathrm{cat}}\right)(\mathrm{A}, \mathrm{C}$, E) and unfolding as recorded by fluorescence emission $(f u)(B, D, F)$ of extremophilic enzymes. AHA, Psychrophilic $\alpha$-amylase (heavy line); PPA, mesophilic $\alpha$-amylase (continuous line); BAA, thermostable $\alpha$-amylase (dashed line); $P h$ lig, psychrophilic DNA ligase (heavy line); Eclig, mesophilic DNA ligase (continuous line); Tslig, thermophilic DNA ligase (dashed line); pXyl, psychrophilic xylanase (heavy line); Xyl1, mesophilic xylanase (continuous line); CelA, thermophilic xylanase (dashed line). Adapted from Refs. 48, 64, 65.

tion of conformational states translated into an increased entropy of this state, compared to that of the mesophilic homologues. The entropic contribution of activation has an unavoidable counter effect on the acquirement of a high specific activity of psychrophilic enzymes but retaining stability in regions of protein not involved in the catalysis could contribute to a reduction in $T \Delta S^{\#}(61)$.

These considerations lead to the idea that the thermode- 
pendence of the reaction rate is only dependent on the catalytic constant $k_{\text {cat }}$. However, an enzymatic reaction is characterized by two fundamental kinetic parameters, $k_{\text {cat }}$ and $K_{\mathrm{m}}$ (which usually represents a measure of the affinity of the enzyme for the substrate), and the specific constant $k_{\text {cat }} / K_{\mathrm{m}}$ is a better indicator of catalytic efficiency than $k_{\text {cat }}$ alone, especially for enzymes working at low substrate concentrations. Among psychrophilic enzymes (for compilations, see Refs. 22 and 66), two main trends are observed: improving $k_{\text {cat }}$ at the expense of $K_{\mathrm{m}}$ (both $k_{\text {cat }}$ and $K_{\mathrm{m}}$ increase) and improving the $k_{\text {cat }} / K_{\mathrm{m}}$ ratio (increase in $k_{\text {cat }}$ and decrease in $K_{\mathrm{m}}$ ). However, most psychrophilic enzymes have higher $K_{\mathrm{m}}$ values than their mesophilic counterparts (67) and increase $k_{\text {cat }}$ at the expense of $K_{\mathrm{m}}$. This weaker substrate binding is predicted to accompany the broader distribution of the groundstate ES if increases in $k_{\text {cat }}$ are achieved through active-site resilience. If the substrate is weakly bound, the ground-state ES falls in a shallower energy pit, reducing the energy barrier $\Delta G^{\#}$ of the reaction and increasing $k_{\text {cat }}$. This is generally observed in psychrophilic enzymes, such as $\alpha$-amylase, which display identical substrate-binding sites and activesite architecture when compared with their mesophilic homologues (42). A correlation between $k_{\text {cat }}$ and $K_{\mathrm{m}}$ was demonstrated by reintroducing in the psychrophilic $\alpha$-amylase from $P$. haloplanktis, some stabilizing weak interactions that were missing when compared to the mesophilic enzyme from the pig pancreas (24). The stabilized mutants displayed decreased $k_{\text {cat }}$ and $K_{\mathrm{m}}$ and support the concept of adaptive drift in the case of enzymes improving $k_{\text {cat }}$ at the expense of $K_{\mathrm{m}}$. However, some enzymes react against this adaptive drift of $K_{\mathrm{m}}$ in order to maintain or improve the substrate-binding affinity. The optimization of the substrate-binding affinity can be obtained by amino acid substitutions within the active site of the psychrophilic enzymes. This is the case for the cold-active extracellular chitobiase from the psychrophilic Arthrobacter sp. TAD20 which improves the $k_{\text {cat }} / K_{\mathrm{m}}$ ratio (increase in $k_{\text {cat }}$ and decrease in $K_{\mathrm{m}}$ ) (26). In the mesophilic chitobiase, two tryptophan residues are the main substrate-binding ligands, which perform hydrophobic interactions with the substrate. These residues are substituted by polar residues in the psychrophilic enzyme and this substitution could lead to the decrease in $K_{\mathrm{m}}$ at low temperatures. Compared to hydrophobic interactions, the polar residues are able to perform, at least within a certain temperature range, stronger interactions as the temperature decreases. Indeed, two types of interaction are involved in the binding of a substrate by enzymes. Hydrophobic interactions occur endothermically around room temperatures and are weakened by a decrease in temperature. Interactions of an electrostatic nature (such as hydrogen bonds and ion pairs) occur exothermically and are stabilized by moderately low temperatures. Consequently, temperature will not only affect $k_{\text {cat }}$ but also $K_{\mathrm{m}}$ and the effect of temperature on $K_{\mathrm{m}}$ could depend on the type of interaction involved in substrate binding. Evolution through an increase in $k_{\text {cat }}$ and a decrease in $K_{\mathrm{m}}$ should be particularly crucial for enzymes typically operating at subsaturating substrate concentrations, such as most intracellular enzymes. Some cold-active intracellular enzymes improve the $k_{\text {cat }} / K_{\mathrm{m}}$ ratio $(28,59,68)$ but some metabolic enzymes such as the psychrophilic dihydrofolate reductase from Moritella profunda sp. nov. (52) and the ornithine carbamoyltransferase from the psychrophilic Moritella abyssi (52) do not optimize the catalytic efficiency $k_{\text {cat }} / K_{\mathrm{m}}$. Both heat-labile enzymes appear to be suboptimal in their physiological temperature range as far as the $k_{\text {cat }} / K_{\mathrm{m}}$ ratio is concerned, supporting the concept that complete metabolic adaptation to cold may remain elusive (52). However, it should be noted that the improvement of the catalytic efficiency $k_{\text {cat }} / K_{\mathrm{m}}$ could be related to the global or localized decrease in the stability of psychrophilic enzymes. Indeed, the psychrophilic $\alpha$-amylase and xylanase (global low stability) improve the $k_{\text {cat }}$ value at low temperatures at the expense of the $K_{\mathrm{m}}$ value, probably as a result of a less efficient substrate binding into the flexible active site. In contrast, the cold-active phosphoglycerate kinase (localized flexibility) displays an improved $K_{\mathrm{m}}$ value with respect to its mesophilic homologue and it has been proposed that keeping a part of the protein rigid may improve the binding of the substrate (65).

Stability of psychrophilic enzymes Psychrophilic enzymes are characterized by their low stability in comparison with their mesophilic and thermophilic homologues. The lower stability of cold-active enzymes arises from the weakening of intramolecular forces contributing to the cohesion of the native protein molecule. The decreased stability of psychrophilic enzymes is well demonstrated by differential scanning calorimetry (DSC) which allows the direct analysis of thermodynamic parameters. The thermal unfolding of proteins adapted to extreme temperatures is particularly well illustrated by thermograms from the psychrophilic, mesophilic and thermophilic $\alpha$-amylases (64), xylanases (65) and DNA ligases (48) recorded by microcalorimetry (Fig. 3). The analysis of the parameters used to characterize the stability of proteins shows common trends. First, the unfolding of cold-active enzymes occurs at lower temperatures, as indicated by the melting point, $T_{\mathrm{m}}$, at the top of the transition. Second, the area below the transition (calorimetric enthalpy of unfolding $\Delta H_{\mathrm{cal}}$ ), representing the total heat absorbed during the unfolding, is much lower for psychrophilic enzymes and there is a clear trend for increasing $\Delta H_{\text {cal }}$ values from psychrophile to thermophile. Third, the unfolding of psychrophilic enzymes is often a cooperative, all-or-nothing process, devoid of stability domains, whereas, for example, mesophilic and thermophilic $\alpha$-amylases and DNA ligases show two and three transitions reflecting the presence of structural units of distinct stabilities.

The analysis of the thermodynamic parameters of activation for the irreversible unfolding of $\alpha$-amylases (mutant N12R of the psychrophilic $\alpha$-amylase), xylanases and DNA ligases shows a higher denaturation rate for the psychrophilic enzymes and correspondingly a lower energy barrier $\left(\Delta G^{\#}\right)$ (Table 1). However, $\Delta H^{\#}$ and $T \Delta S^{\#}$ are highest for the psychrophilic enzymes, indicating that their lower thermostability is due to an unfavorable entropic contribution. These parameters show an increasing stability of mesophilic and thermophilic enzymes with temperature and support the concept of a continuum in protein adaptation to temperature.

According to these results, the cold adaptation of the psychrophilic $\alpha$-amylase, xylanase and DNA ligase is clearly 

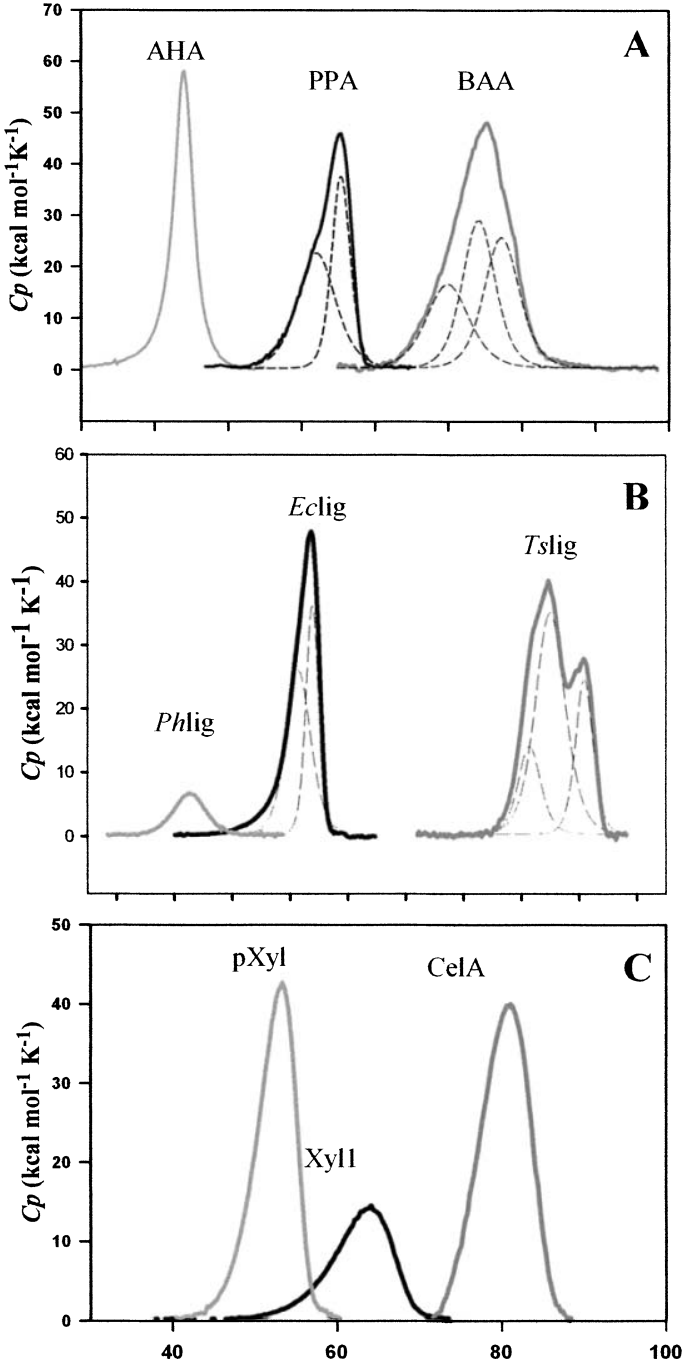

Temperature $\left({ }^{\circ} \mathrm{C}\right)$

FIG. 3. Thermal unfolding of the psychrophilic, mesophilic and thermophilic $\alpha$-amylases (A), DNA ligases (B) and xylanases (C) recorded by differential scanning calorimetry (DSC). AHA, Psychrophilic $\alpha$-amylase; PPA, mesophilic $\alpha$-amylase; BAA, thermostable $\alpha$-amylase; Phlig, psychrophilic DNA ligase; Eclig, mesophilic DNA ligase; Tslig, thermophilic DNA ligase; pXyl, psychrophilic xylanase; Xyl1, mesophilic xylanase; CelA, thermophilic xylanase. Adapted from Refs. 48, 64, 65. The lower molecular mass of the mesophilic xylanase gives rise to the observed low calorimetric enthalpy. When compared with psychrophilic enzymes, mesophilic and thermophilic homologues are characterized by higher $T_{\mathrm{m}}$ (top of the transition) and $\Delta H_{\mathrm{cal}}$ (area under the transition) values and are made of structural units of distinct stabilities (shown as dashed lines for the mesophilic and thermophilic $\alpha$-amylases and DNA ligases).

correlated to the general weakening of intramolecular interactions, leading to an overall decrease in the thermostability of the protein. A decrease in global stability may in turn provide the appropriate plasticity around the catalytic residues necessary to adapt the catalytic efficiency to low temperatures. However, as previously mentioned, the reduced stability related to the low stability of the psychrophilic enzyme may not necessarily arise from the general reduction in the strength of intramolecular forces, but from the weak-
TABLE 1. Thermodynamic parameters for irreversible thermal unfolding

\begin{tabular}{lccc} 
Enzyme & $\begin{array}{c}\Delta G^{\#} \\
\left(\mathrm{~kJ} \mathrm{~mol}^{-1}\right)\end{array}$ & $\begin{array}{c}\Delta H^{\#} \\
\left(\mathrm{~kJ} \mathrm{~mol}^{-1}\right)\end{array}$ & $\begin{array}{c}T \Delta S^{\#} \\
\left(\mathrm{~kJ} \mathrm{~mol}^{-1}\right)\end{array}$ \\
\hline $\begin{array}{l}\alpha \text {-Amylases }^{\mathrm{a}} \\
\text { AHA }\end{array}$ & 85.7 & 458.5 & 372.8 \\
PPA & 89.8 & 354.0 & 264.2 \\
BAA & 95.8 & 310.1 & 214.3 \\
Xylanases & & & \\
pXyl & 82.0 & 414.0 & 332.0 \\
CelA & 113.0 & 345.0 & 232.0 \\
DNA ligases & & & \\
Phlig & 93.5 & 422.2 & 328.7 \\
Eclig & 98.1 & 162.1 & 64.0 \\
\hline
\end{tabular}

${ }^{\text {a }} k=0.05 \mathrm{~s}^{-1}$. Activation data are reported for an identical rate constant for three $\alpha$-amylases (psychrophilic AHA, mesophilic PPA and thermophilic BAA). Adapted from Ref. 64.

${ }^{\mathrm{b}} k=1.7 \mathrm{~s}^{-1}$ for $\mathrm{pXyl}$ (psychrophilic xylanase) and $k=1.9 \times 10^{-5}$ for CelA (thermophilic xylanase). Parameters recorded at $65^{\circ} \mathrm{C}$. Adapted from Ref. 65.

${ }^{\mathrm{c}} k=3.4 \times 10^{-5} \mathrm{~s}^{-1}$ for Phlig psychrophilic DNA ligase and Eclig mesophilic DNA ligase. Adapted from Ref. 48.

ened interactions in one or a few important regions of the structure (localized flexibility) $(26,28,32,63)$. Lines of direct evidence of differences in stability between some domains and the entire structure have been provided by DSC studies $(28,26)$. In these cases, cold-adapted enzymes contain some elements controlling protein stability and affinity for the substrate and other elements conferring the required flexibility for an efficient catalysis at the environmental temperature.

Among psychrophilic enzymes showing a global reduction in stability, some proteins unfold according to a reversible pathway without any stable intermediates between the native and unfolded states. This is the case of the psychrophilic $\alpha$-amylase from $P$. haloplanktis that unfolds reversibly according to a two-state mechanism, while its mesophilic and thermophilic homologues unfold irreversibly with a number of transitions. This reversibility associated with a two-state unfolding allows the study of the temperature-dependent thermodynamic stability function according to the Gibbs free-energy change between the denatured and native states $\left(\Delta G_{N-U}\right)$ of the protein using the Gibbs-Helmholtz equation (69). This reversible character can be related to the weak hydrophobicity of the core clusters in the coldadapted enzyme and to the low melting temperature, at which hydrophobic interactions are restrained because, unlike mesophilic $\alpha$-amylases, aggregation does not occur. The stability curves in Fig. 4 represent the Gibbs free energy of unfolding as a function of temperature and correspond to the energy required to disrupt the protein structure at any given temperature. Compared to mesophilic and thermophilic proteins, the cold-active $\alpha$-amylase shows a global collapse of its stability curve and its conformational energy $\left(\Delta G_{N-U}=92 \mathrm{~J} / \mathrm{mol} /\right.$ residue $)$ is the lowest value reported for two-state proteins (70). The psychrophilic $\alpha$-amylase has reached a state close to the lowest possible stability of the native state, thereby preventing any further decrease in stability. If an increase in flexibility is gained at the expense of stability, this implies that the actual native state precludes any further adaptation toward a more flexible structure. 


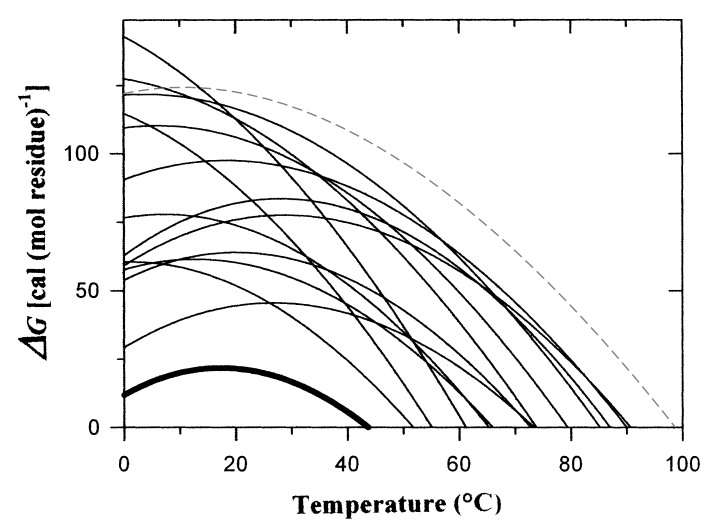

FIG. 4. Gibbs free energy of unfolding or conformational stability. Stability curves for a psychrophilic $\alpha$-amylase (heavy line), several mesophilic proteins (continuous lines) and a thermophilic protein (dashed line). To compare proteins of various sizes, the free energy is expressed in specific units per mole of residue. Adapted from Ref. 70 .

Consequently, the specific activity of the cold-adapted enzyme at the environmental temperature is still much lower than that of the mesophilic counterpart at $37^{\circ} \mathrm{C}$, reflecting the imperfect adaptation of psychrophilic enzymes. The stability curve is a parabolic function limited by the temperature of cold denaturation $T_{\mathrm{m}}$ (below $0^{\circ} \mathrm{C}$ ) and by the high temperature melting point $T_{\mathrm{m}}$ at which by definition $\Delta G_{N-U}=$ 0 (71). The curve shows that psychrophilic proteins are both heat labile and cold labile. Indeed, a decrease in stability, indicated on the left side of the stability curve of the psychrophilic enzyme, leads to cold denaturation. The extrapolation of the curve of the cold-active $\alpha$-amylase below $0^{\circ} \mathrm{C}$ predicts cold unfolding at $\sim-10^{\circ} \mathrm{C}$ in vitro. It is thought that cold denaturation arises from the hydration of protein groups which destabilizes the protein at decreasing temperature (72). The hydration of polar and aromatic groups, in particular, is associated with a negative free energy and destabilizes the protein structure. The group hydration responsible for the decrease in $\Delta G_{\text {stab }}$ at low temperatures could contribute to the conformational flexibility of psychrophilic enzymes in their natural environment. This is different from mesophilic and thermophilic proteins, the latter taking advantage of the conformational entropy rise with temperature to gain plasticity. Group hydration seems to play an essential role in the acquisition of flexibility as improved interactions with the solvent have been noted for some cold-active enzymes. However, in certain cases, the higher fraction of the apolar molecular surface and the lower accessible area may prevent the effect of cold denaturation $(23,72)$. The psychrophilic adenylate kinase AKglo has been observed to have an approximately 200 square $\AA$ more apolar surface area than the mesophilic AKsub and the thermophilic AKste, suggesting that protection against cold denaturation might include a design selection that has a more "strategically" pre-exposed hydrophobic surface so as not to risk losing native configurations due to this effect (47).

Relationships between activity and stability Relationships between activity and stability are well illustrated by the folding funnel model (64). In this model, the conformational stability of psychrophilic and thermophilic enzymes is represented as a function of conformational diver-

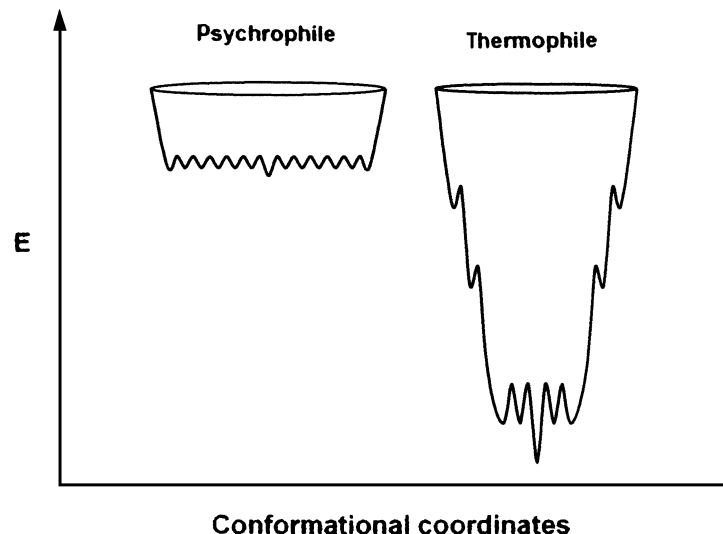

FIG. 5. Proposed model of folding funnels for psychrophilic and thermophilic enzymes. In these shematic energy landscapes, the conformational stability $(\mathrm{E})$ is represented as a function of conformational diversity. Adapted from Ref. 64.

sity in shematic energy landscapes (Fig. 5). The height of the funnel, which represents the conformational stability (free energy of folding), is higher for the thermophilic enzymes and the upper edge of the funnel, occupied by the unfolded state in a random coil conformation, is larger for the cold-adapted enzymes. During folding, the free-energy level decreases as well as the conformational ensemble. The funnel slopes of psychrophilic enzymes are steep and smooth and reflect the cooperative unfolding without intermediates characterizing the cold-adapted enzymes as a result of fewer stabilising interactions and stability domains. In contrast, the thermophilic proteins pass through intermediate states corresponding to the local minima of energy. These minima are responsible for the ruggedness of the funnel slopes and for the reduced cooperativity of the folding-unfolding reaction. The bottom of the funnel, which represents the stability of the native state ensemble, can be depicted as a single global minimum with a high energy barrier for a very stable and rigid thermophilic protein, whereas the bottom for an unstable and flexible psychrophilic protein is rugged and depicts a large population of conformers with a low energy barrier between them. The rigidity of the native state is therefore a direct function of energy barrier height $(73,74)$. In this context, the activity-stability relationships in these extremoenzymes depend on the bottom properties. Indeed, it has been argued that upon substrate binding to the association-competent subpopulation, the equilibrium between all conformers is shifted toward this subpopulation, leading to the active conformational ensemble (73-75). In the case of the rugged bottom of psychrophilic enzymes and in contrast with thermophilic proteins, this equilibrium shift only requires a modest free-energy change (low energy barriers) and a small enthalpy change for the interconversion of the conformations, but is accompanied by a large entropy change for fluctuations between the wide conformer ensemble.

The site-directed mutagenesis of the psychrophilic $\alpha$-amylase has provided strong experimental support for the adaptive relationships between stability and activity $(24,25)$. Mutants have revealed the individual contribution of a weak interaction and of an additional disulfide bond to protein stability as shown by the increases in $T_{\mathrm{m}}$ (melting point) and 
$\Delta H_{\text {cal }}$ (calorimetric enthalpy), by the modifications of unfolding cooperativity and reversibility, by the appearance of stability domains, and by the modification of the thermal inactivation rate constant $k_{\mathrm{i}}$ and of the kinetic parameters $k_{\text {cat }}$ and $K_{\mathrm{m}}$. The stabilization of the psychrophilic enzyme seems to decrease the activity by altering the dynamic properties of residues in the active site, but increases the affinity for the substrate, probably by improving its binding into the more rigid catalytic center of the mutant.

In contrast, laboratory evolution has shown that, in few cases, the stability and activity of proteins are not strictly linked, giving rise to the proposal that the low stability of cold-active enzymes results from a genetic drift originating from the lack of selective pressure for stable proteins (76). Directed evolution experiments can indeed yield synthetic catalysts that are thermostable and active either at high (77) or low $(78,79)$ temperatures. However, when random mutants of mesophilic and thermophilic enzymes were only screened for high activity at low temperatures during directed evolution (80-85), the evolved enzymes generally display a concomitant reduced thermostability. Moreover, in multidomain psychrophilic enzymes that contain both catalytic and noncatalytic domains as described for the psychrophilic chitobiase (26), the catalytic domain is always heatlabile, whereas the noncatalytic domain can be stable, even more than that of mesophilic proteins. It is therefore unlikely that genetic drift affects only the catalytic domain without modifying other regions of the protein. If it appears possible, at least under laboratory conditions, to uncouple activity and stability, enzymes displaying a high stability together with a high flexibility and activity do not exist in nature, except for thermophilic enzymes that catalyze the conversion of labile metabolic intermediates (86).

Thus the low stability of psychrophilic enzymes could be the simplest adaptive strategy that provides a gain in activity in the absence of selection for stable proteins in cold environments but in the presence of a strong selective pressure for highly active enzymes.

Flexibility strategy Maintaining the appropriate balance between molecular stability and structural flexibility is necessary for protein functions. Stability is needed to ensure the appropriate geometry for ligand binding, as well as to avoid denaturation, while flexibility is necessary to allow a catalysis at a metabolically appropriate rate (87). Psychrophilic enzymes are characterized by an increase in the plasticity or flexibility of all or some parts of the molecular structure in order to compensate for the lower thermal energy provided by the low-temperature habitat (88). This flexibility could be related to the low stability characterizing coldadapted enzymes. Indeed, recent experiments involving the dynamic quenching of fluorescence, which shows an increased permeability to a small quencher, strongly support the concept of high flexibility of psychrophilic enzymes (48, $64,65)$. In all cases, fluorescence quenching performed on psychrophilic, mesophilic and/or thermophilic enzymes revealed that the variation of fluorescence quenching between low and moderate temperatures decreases in the order psychrophile $\rightarrow$ mesophile $\rightarrow$ thermophile (Fig. 6). These results indicate a greater permeability of cold-adapted enzymes to the quencher, reflecting a strong correlation be-
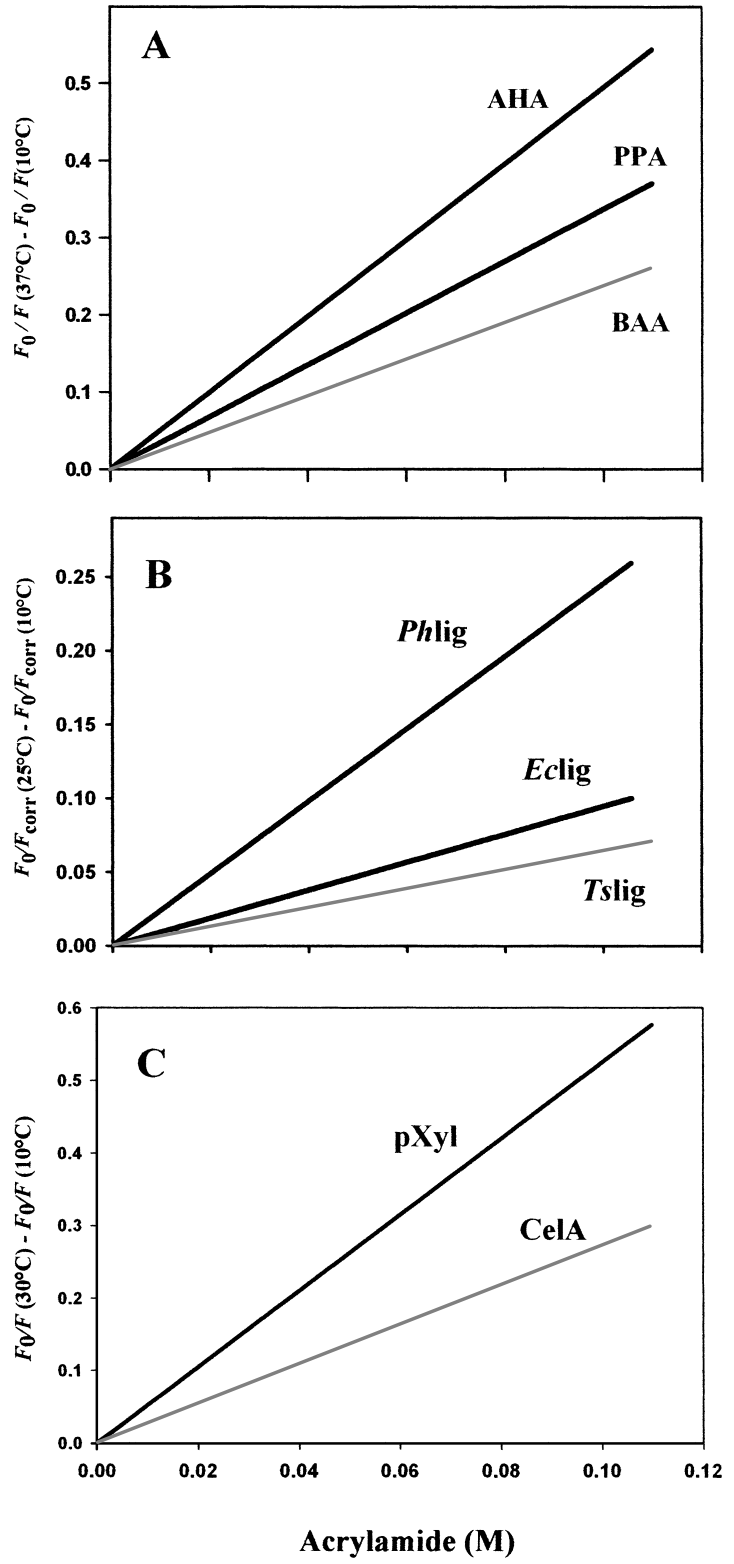

FIG. 6. Conformational flexibility of psychrophilic, mesophilic and thermophilic $\alpha$-amylases (A), DNA ligases (B) and xylanases (C). Curves representing the acrylamide quenching of the tryptophan fluorescence of AHA; PPA, mesophilic $\alpha$-amylase; BAA, thermostable $\alpha$-amylase; Phlig, psychrophilic DNA ligase; Eclig, mesophilic DNA ligase; $T s$ lig, thermophilic DNA ligase; $\mathrm{pXyl}$, psychrophilic xylanase; and CelA, thermophilic xylanase. In order to abolish the artifactual effect of additional tryptophan present in the mesophilic and thermophilic enzymes, the differences in fluorescence ratios $F_{0} / F$ at moderate $\left(25^{\circ} \mathrm{C}, 30^{\circ} \mathrm{C}\right.$ and $\left.37^{\circ} \mathrm{C}\right)$ and low temperatures $\left(10^{\circ} \mathrm{C}\right)$ were plotted as a function of acrylamide concentration (mM). Adapted from Refs. 48, 64,65 .

tween flexibility and conformational stability.

In this technique, the decrease in fluorescence arising from diffusive collisions between the quencher and the fluorophore reflects the ability of the quencher to penetrate accessible regions of the protein structure and can consequently be viewed as an index of protein permeability. This is a dynamic process that allows the measurement of con- 
formational motions over a large time scale (picoseconds to seconds). Nevertheless, it would be interesting to define the flexibility of cold enzymes in terms of type, amplitude and time scale of molecular motions. These aspects are now being studied by neutron scattering, which provides a unique tool to study atomic thermal motions in macromolecules, because neutron wavelengths and energies, respectively, match motion amplitudes and frequencies (89). Measured variables are the mean square amplitudes in a given time scale, as a function of temperature, from which an effective mean force constant, determining macromolecular resilience, can be calculated (90). Nevertheless, at this stage, the relationships between activity, stability and flexibility remain poorly understood in psychrophilic enzymes. These relationships have found some experimental support from the comparison of thermophilic and mesophilic enzymes (91-93), but the results obtained for probing the protein flexibility strategy in psychrophilic enzymes are controversial $(87,94,95)$. This could be related to the technique used in these studies, global hydrogen-deuterium exchange measured over inappropriate time scales, while it is likely that the increase in the flexibility of cold-adapted enzymes is local and on the microsecond to millisecond time scale, i.e., directly related to the active site and catalytic activity. However, some studies report that thermostability is not incompatible with high activity at moderate temperatures $(86,96,97)$ because protein stability can be achieved through an increase in the entropy of the native state as in the case of the $\beta$-glucosidase from Sulfolobus solfariticus (98). Moreover, other results show that relationships between flexibility and stability or activity are more complex than expected intuitively (99-101).

Potential for biotechnological applications One of the main interest of psychrophilic enzymes in biotechnological applications is the lack of requirement for expensive heating steps and consecutive economic benefits through energy saving. Other economic benefits originate from their abilities to function in a cold environment, to increase the reaction yield, to accommodate a high level of stereospecificity, and to minimize undesirable chemical reactions that can occur at higher temperatures (66). Moreover, they prevent the requirements of an increase in enzyme concentration to compensate for the lower efficacy when using mesophilic enzymes at low temperatures. These enzymes are also characterized by their thermal lability which allows an easy and rapid inactivation when required. This rapid inactivation of cold-active enzymes by mild heat treatment preserves product quality, permits selective enzyme inactivation in a complex medium, and does not require expensive heating/cooling systems (102). The ability to heat-inactivate cold-active enzymes is particularly useful in food industry where it is important to prevent any modifications of the original heat-sensitive substrates and products. This is also useful in sequential processes such as molecular biology where the actions of an enzyme must be terminated before the next process is undertaken (66). The biotechnological potential of psychrophilic enzymes is enhanced by the demonstration that recombinant cold-active enzymes are undistinguishable from their wild-type parent molecules with regards to kinetic parameters, folding properties (103) and three-dimensional structures (42), when the enzymes are expressed at sufficiently low temperatures $\left(15-18^{\circ} \mathrm{C}\right)$. Moreover, expression at low temperatures is now possible as shown by the construction of a host-vector system that allows the overexpression of genes in psychrophilic bacteria (104). This study revealed a new biotechnological potential of psychrophilic strains as the expression at low temperatures prevents the formation of inclusion bodies and protects heat-sensitive gene products. Other host-vector systems for a temperature-regulated gene expression, allowing the overproduction of thermolabile enzymes originating from psychrophiles, have also been patented (Schweder, T., patent DE10101266, 2002; Kann, T. and Schweder, T., patent EP1224307, 2002). In other respects, the improvement of the competencies of psychrophilic enzymes, according to the requirement of a biotechnological process, could be obtained by directed mutagenesis or perhaps more quickly by the directed evolution of the recombinant enzyme. Possible applications of cold-adapted enzymes can be found in numerous biotechnological and industrial fields as tools in molecular biology, food, drinks, textile and detergent industries, and bioremediation (for review, see Refs. 66, 102, 105). However, despite a large number of possible biotechnological applications, only a few cold-adapted enzymes are in commercial use. The costs of production and processing at low temperatures remain probably higher than those for the commercial enzymes that are presently in use. Nevertheless, patent protection for enzymes from psychrophilic organisms is slowly increasing (Hasan, A.K.M.Q. and Tamiya, E., patent WO9730172, 1997; Hasan, A.K.M.Q. and Tamiya, E., patent US6200793, 1998; Kubota, H. et al., patent WO9743406, 1996; François, J.M. et al., patent WO0104276, 2001; Genot, B. et al., patent WO2004023879, 2004).

\section{CONCLUSIONS}

The actual availability of crystal structures of psychrophilic, mesophilic and thermophilic homologous enzymes enables the investigation of the different aspects of protein adaptation to cold and the continuum in the strategy of protein adaptation to temperature. Moreover, the availability of the first genome-sequence data enables the investigation of more psychrophilic aspects of such as temperature sensors (18). The high activity characterizing psychrophilic enzymes is the main adaptive parameter to low temperatures and seems to be achieved by the destabilization of the active site or of the entire protein structure, allowing the catalytic center to be more flexible at low temperatures. However, the relationships between activity, flexibility and stability are still the subject of controversy. A definition of flexibility in terms of the type, amplitude and time scale of molecular motions related to the catalytic efficiency would be helpful in understanding these relationships. It was demonstrated that each psychrophilic enzyme adopts its own adaptive strategy. In terms of protein evolution, one could say that the adaptive strategy observed in natural cold environments could be, at least in some cases, a result of the lack of selective pressure for stable proteins, in conjunction with a strong selection for highly active enzymes. In addition to a powerful potential in fundamental research and particularly in protein dynamic and folding investigations, psychrophilic enzymes have a 
huge potential for biotechnological purposes.

\section{ACKNOWLEDGMENTS}

The authors are grateful to N. Gerardin, R. Marchand and A. Dernier for their skilful technical assistance. The authors are also grateful to the financial support provided by the European Union, the Region Wallonne and the FNRS Belgium. The support of the Institut Français de Recherche et de Technologie Polaire is also highly appreciated.

\section{REFERENCES}

1. Forster, J.: Ueber einige Eigenschaften leuchtender Bakterien. Centr. Bakteriol. Parasitenk., 2, 337-340 (1887).

2. Schmidt-Nielsen, S.: Centralbl. Bakteriol. Parasitenkd. II Abt., 9, 145-147 (1902).

3. Margesin, R., Feller, G., Gerday, C., and Russell, N. J.: Cold-adapted microorganisms: adaptation strategies and biotechnological potential, p. 871-885. In Bitton, G. (ed.), The encyclopedia of environmental microbiology. Wiley, New York (2002).

4. Morita, R. Y.: Psychrophilic bacteria. Bacteriol. Rev., 39, 144-167 (1975).

5. Feller, G., Narinx, E., Arpigny, J.-L., Zekhnini, Z., Swings, J., and Gerday, C.: Temperature dependence of growth, enzyme secretion and activity of psychrophilic Antarctic bacteria. Appl. Microbiol. Biotechnol., 41, 477-479 (1994).

6. Russell, N. J.: Toward a molecular understanding of cold activity of enzymes from psychrophiles. Extremophiles, 4, 83-90 (2000).

7. Bowman, J. P., McCammon, S. A., Brown, M. V., Nichols, D. S., and McMeekin, T. A.: Diversity and association of psychrophilic bacteria in Antarctic sea ice. Appl. Environ. Microbiol., 63, 3068-3078 (1997).

8. Margesin, R. and Schinner, F.: Efficiency of indigenous and inoculated cold-adapted soil microorganisms for biodegradation of diesel oil in alpine soils. Appl. Environ. Microbiol., 63, 2660-2664 (1997).

9. Morita, Y., Nakamura, T., Hasan, Q., Murakami, Y., Yokoyama, K., and Tamiya, E.: Cold-active enzymes from cold-adapted bacteria. J. Am. Oil. Chem. Soc., 74, 441-444 (1997).

10. Deming, J. W.: Psychrophiles and polar regions. Curr. Opin. Microbiol., 5, 301-309 (2002).

11. Yayanos, A. A.: Microbiology to 10,500 meters in the deep sea. Annu. Rev. Microbiol., 49, 777-805 (1995).

12. Ewart, K. V., Lin, Q., and Hew, C. L.: Structure, function and evolution of antifreeze proteins. Cell. Mol. Life Sci., 55, 271-283 (1999).

13. Russell, N. J. and Hamamoto, T.: Psychrophiles, p. 25-45. In Horikoshi, K. and Grant, D. (ed.), Extremophiles: microbial life in extreme environments. Wiley-Liss, New York (1998).

14. Ermolenko, D. N. and Makhatadze, G. I.: Bacterial coldshock proteins. Cell. Mol. Life Sci., 59, 1902-1913 (2002).

15. Hebraud, M. and Guzzo, J.: The main cold shock protein of Listeria monocytogenes belongs to the family of ferritinlike proteins. FEMS Microbiol. Lett., 190, 29-34 (2000).

16. Berger, F., Normand, P., and Potier, P.: $\operatorname{cap} A$, a $\operatorname{csp} A$-like gene that encodes a cold acclimation protein in the psychrotrophic bacterium Arthrobacter globiformis SI55. J. Bacteriol., 179, 5670-5676 (1997).

17. Michel, V., Lehoux, I., Depret, G., Anglade, P., Labadie, J., and Hebraud, M.: The cold shock response of the psychrotrophic bacterium Pseudomonas fragi involves four lowmolecular-mass nucleic acid-binding proteins. J. Bacteriol., 179, 7331-7342 (1997).
18. Saunders, N. F., Thomas, T., Curmi, P. M., Mattick, J. S., Kuczek, E., Slade, R., Davis, J., Franzmann, P. D., Boone, D., Rusterholtz, K., and 15 other authors: Mechanisms of thermal adaptation revealed from the genomes of the Antarctic Archaea Methanogenium frigidum and Methanococcoides burtonii. Genome Res., 13, 1580-1588 (2003).

19. Detrich, H. W., 3rd: Molecular adaptation of microtubules and microtubules motors from Antarctic fish, p. 139-149. In di Prisco, G., Pisano, E., and Clarke, A. (ed.), Fishes of Antarctica. A biological review. Springer-Verlag, Milano (1998).

20. Detrich, H. W., 3rd, Parker, S. K., Williams, R. C., Jr., Nogales, E., and Downing, K. H.: Cold adaptation of microtubule assembly and dynamics. Structural interpretation of primary sequence changes present in the $\alpha$ - and $\beta$-tubulins of Antarctic fishes. J. Biol. Chem., 275, 37038-37047 (2000).

21. Willem, S., Srahna, M., Devos, N., Gerday, C., Loppes, R., and Matagne, R. F.: Protein adaptation to low temperatures: a comparative study of $\alpha$-tubulin sequences in mesophilic and psychrophilic algae. Extremophiles, 3, 221226 (1999)

22. Smalas, A. O., Leiros, H. K., Os, V., and Willassen, N. P.: Cold adapted enzymes. Biotechnol. Annu. Rev., 6, 1-57 (2000).

23. Gianese, G., Bossa, F., and Pascarella, S.: Comparative structural analysis of psychrophilic and meso- and thermophilic enzymes. Proteins, 47, 236-249 (2002).

24. D'Amico, S., Gerday, C., and Feller, G.: Structural determinants of cold adaptation and stability in a large protein. J. Biol. Chem., 276, 25791-25796 (2001)

25. D'Amico, S., Gerday, C., and Feller, G.: Temperature adaptation of proteins: engineering mesophilic-like activity and stability in a cold-adapted $\alpha$-amylase. J. Mol. Biol., 332 981-988 (2003).

26. Lonhienne, T., Zoidakis, J., Vorgias, C. E., Feller, G., Gerday, C., and Bouriotis, V.: Modular structure, local flexibility and cold-activity of a novel chitobiase from a psychrophilic Antarctic bacterium. J. Mol. Biol., 310, 291-297 (2001).

27. Feller, G., D'Amico, S., Benotmane, A. M., Joly, F., Van Beeumen, J., and Gerday, C.: Characterization of the $\mathrm{C}$-terminal propeptide involved in bacterial wall spanning of $\alpha$-amylase from the psychrophile Alteromonas haloplanctis. J. Biol. Chem., 273, 12109-12115 (1998).

28. Bentahir, M., Feller, G., Aittaleb, M., Lamotte-Brasseur, J., Himri, T., Chessa, J. P., and Gerday, C.: Structural, kinetic, and calorimetric characterization of the cold-active phosphoglycerate kinase from the antarctic Pseudomonas sp. TACII18. J. Biol. Chem., 275, 11147-11153 (2000).

29. Leiros, I., Moe, E., Lanes, O., Smalas, A. O., and Willassen, N. P.: The structure of uracil-DNA glycosylase from Atlantic cod (Gadus morhua) reveals cold-adaptation features. Acta Crystallogr. D Biol. Crystallogr., 59, 1357-1365 (2003).

30. Aghajari, N., Van Petegem, F., Villeret, V., Chessa, J. P., Gerday, C., Haser, R., and Van Beeumen, J.: Crystal structures of a psychrophilic metalloprotease reveal new insights into catalysis by cold-adapted proteases. Proteins, 50, 636647 (2003)

31. Van Petegem, F., Collins, T., Meuwis, M. A., Gerday, C., Feller, G., and Van Beeumen, J.: The structure of a coldadapted family 8 xylanase at $1.3 \AA$ resolution, structural adaptations to cold and investigation of the active site. J. Biol. Chem., 278, 7531-7539 (2003).

32. Russell, R. J., Gerike, U., Danson, M. J., Hough, D. W., and Taylor, G. L.: Structural adaptations of the cold-active citrate synthase from an Antarctic bacterium. Structure, 6 , 351-361 (1998).

33. Aghajari, N., Feller, G., Gerday, C., and Haser, R.: Crys- 
tal structures of the psychrophilic $\alpha$-amylase from Alteromonas haloplanctis in its native form and complexed with an inhibitor. Protein Sci., 7, 564-572 (1998).

34. Alvarez, M., Zeelen, J. P., Mainfroid, V., Rentier-Delrue, F., Martial, J. A., Wyns, L., Wierenga, R. K., and Maes, D.: Triose-phosphate isomerase (TIM) of the psychrophilic bacterium Vibrio marinus. Kinetic and structural properties. J. Biol. Chem., 273, 2199-2206 (1998).

35. Kim, S. Y., Hwang, K. Y., Kim, S. H., Sung, H. C., Han, Y.S., and Cho, Y. J.: Structural basis for cold adaptation. Sequence, biochemical properties, and crystal structure of malate dehydrogenase from a psychrophile Aquaspirillium arcticum. J. Biol. Chem., 274, 11761-11767 (1999)

36. de Backer, M., McSweeney, S., Rasmussen, H. B., Riise, B. W., Lindley, P., and Hough, E.: The $1.9 \AA$ crystal structure of heat-labile shrimp alkaline phosphatase. J. Mol. Biol., 318, 1265-1274 (2002).

37. Smalas, A. O., Heimstad, E. S., Hordvik, A., Willassen, N. P., and Male, R.: Cold adaption of enzymes: structural comparison between salmon and bovine trypsins. Proteins, 20, 149-166 (1994).

38. Toyota, E., Ng, K. K., Kuninaga, S., Sekizaki, H., Itoh, K., Tanizawa, K., and James, M. N.: Crystal structure and nucleotide sequence of an anionic trypsin from chum salmon (Oncorhynchus keta) in comparison with Atlantic salmon (Salmo salar) and bovine trypsin. J. Mol. Biol., 324, 391397 (2002).

39. Berglund, G. I., Willassen, N. P., Horvik, A., and Smalas, A. O.: Structure of native pancreatic elastase from North Atlantic salmon at $1.61 \AA$ resolution. Acta Cryst. D Biol. Crystallogr., D51, 925-937 (1995).

40. Karlsen, S., Hough, E., and Olsen, R. L.: Structure and proposed amino-acid sequence of a pepsin from atlantic cod (Gadus morhua). Acta Crystallogr. D Biol. Crystallogr., 54, 32-46 (1998).

41. Matsuura, A., Yao, M., Aizawa, T., Koganesawa, N., Masaki, K., Miyazawa, M., Demura, M., Tanaka, I., Kawano, K., and Nitta, K.: Structural analysis of an insect lysozyme exhibiting catalytic efficiency at low temperatures. Biochemistry, 41, 12086-12092 (2002).

42. Aghajari, N., Feller, G., Gerday, C., and Haser, R.: Structures of the psychrophilic Alteromonas haloplanctis $\alpha$-amylase give insights into cold adaptation at a molecular level. Structure, 6, 1503-1516 (1998).

43. Violot, S., Haser, R., Sonan, G., Georlette, D., Feller, G., and Aghajari, N.: Expression, purification, crystallization and preliminary X-ray crystallographic studies of a psychrophilic cellulase from Pseudoalteromonas haloplanktis. Acta Crystallogr. D Biol. Crystallogr., 59, 1256-1258 (2003).

44. Tsuruta, H., Mikami, B., Yamamoto, C., and Aizono, Y.: Crystallization and preliminary X-ray studies of cold-active protein-tyrosine phosphatase of Shewanella sp. Acta Crystallogr. D Biol. Crystallogr., 58, 1465-1466 (2002).

45. Mandelman, D., Bentahir, M., Feller, G., Gerday, C., and Haser, R.: Crystallization and preliminary X-ray analysis of a bacterial psychrophilic enzyme, phosphoglycerate kinase. Acta Crystallogr. D Biol. Crystallogr., 57, 1666-1668 (2001).

46. Bell, G. S., Russell, R. J., Connaris, H., Hough, D. W., Danson, M. J., and Taylor, G. L.: Stepwise adaptations of citrate synthase to survival at life's extremes. From psychrophile to hyperthermophile. Eur. J. Biochem., 269, 62506260 (2002).

47. Bae, E. and Phillips, G. N., Jr.: Structures and analysis of highly homologous psychrophilic, mesophilic, and thermophilic adenylate kinases. J. Biol. Chem., 279, 28202-28208 (2004).

48. Georlette, D., Damien, B., Blaise, V., Depiereux, E. Uversky, V. N., Gerday, C., and Feller, G.: Structural and functional adaptations to extreme temperatures in psychro- philic, mesophilic, and thermophilic DNA ligases. J. Biol. Chem., 278, 37015-37023 (2003).

49. Aghajari, N., Roth, M., and Haser, R.: Crystallographic evidence of a transglycosylation reaction: ternary complexes of a psychrophilic $\alpha$-amylase. Biochemistry, 41, 4273-4280 (2002).

50. Vieille, C. and Zeikus, G. J.: Hyperthermophilic enzymes: sources, uses, and molecular mechanisms for thermostability. Microbiol. Mol. Biol. Rev., 65, 1-43 (2001).

51. Dams, T., Auerbach, G., Bader, G., Jacob, U., Ploom, T., Huber, R., and Jaenicke, R.: The crystal structure of dihydrofolate reductase from Thermotoga maritima: molecular features of thermostability. J. Mol. Biol., 297, 659-672 (2000).

52. Xu, Y., Feller, G., Gerday, C., and Glansdorff, N.: Moritella cold-active dihydrofolate reductase: are there natural limits to optimization of catalytic efficiency at low temperature? J Bacteriol., 185, 5519-5526 (2003).

53. Villeret, V., Clantin, B., Tricot, C., Legrain, C., Roovers, M., Stalon, V., Glansdorff, N., and Van Beeumen, J.: The crystal structure of Pyrococcus furiosus ornithine carbamoyltransferase reveals a key role for oligomerization in enzyme stability at extremely high temperatures. Proc. Natl. Acad. Sci. USA, 95, 2801-2806 (1998).

54. Neet, K. E. and Timm, D. E.: Conformational stability of dimeric proteins: quantitative studies by equilibrium denaturation. Protein Sci., 3, 2167-2174 (1994).

55. Kirino, H., Aoki, M., Aoshima, M., Hayashi, Y., Ohba, M., Yamagishi, A., Wakagi, T., and Oshima, T.: Hydrophobic interaction at the subunit interface contributes to the thermostability of 3-isopropylmalate dehydrogenase from an extreme thermophile, Thermus thermophilus. Eur. J. Biochem., 220, 275-281 (1994).

56. Moriyama, H., Onodera, K., Sakurai, M., Tanaka, N., Kirino-Kagawa, H., Oshima, T., and Katsube, Y.: The crystal structures of mutated 3-isopropylmalate dehydrogenase from Thermus thermophilus HB8 and their relationship to the thermostability of the enzyme. J. Biochem. (Tokyo), 117, 408-413 (1995).

57. Rentier-Delrue, F., Mande, S. C., Moyens, S., Terpstra, P., Mainfroid, V., Goraj, K., Lion, M., Hol, W. G., and Martial, J. A.: Cloning and overexpression of the triosephosphate isomerase genes from psychrophilic and thermophilic bacteria. Structural comparison of the predicted protein sequences. J. Mol. Biol., 229, 85-93 (1993).

58. Kumar, S. and Nussinov, R.: Different roles of electrostatics in heat and in cold: adaptation by citrate synthase. Chembiochem, 5, 280-290 (2004).

59. Hoyoux, A., Jennes, I., Dubois, P., Genicot, S., Dubail, F., Francois, J.M., Baise, E., Feller, G., and Gerday, C.: Cold-adapted $\beta$-galactosidase from the Antarctic psychrophile Pseudoalteromonas haloplanktis. Appl. Environ. Microbiol., 67, 1529-1535 (2001).

60. Juers, D. H., Jacobson, R. H., Wigley, D., Zhang, X. J., Huber, R. E., Tronrud, D. E., and Matthews, B. W.: High resolution refinement of $\beta$-galactosidase in a new crystal form reveals multiple metal-binding sites and provides a structural basis for $\alpha$-complementation. Protein Sci., 9, 16851699 (2000).

61. Lonhienne, T., Gerday, C., and Feller, G.: Psychrophilic enzymes: revisiting the thermodynamic parameters of activation may explain local flexibility. Biochim. Biophys. Acta, 1543, 1-10 (2000).

62. Kramers, H. A.: Brownian motion in field of force and the diffusion model of chemical reactions. Physica, 7, 284-304 (1940)

63. Fields, P. A. and Somero, G. N.: Hot spots in cold adaptation: localized increases in conformational flexibility in lactate dehydrogenase A(4) orthologs of Antarctic notothenioid 
fishes. Proc. Natl. Acad. Sci. USA, 95, 11476-11481 (1998).

64. D'Amico, S., Marx, J. C., Gerday, C., and Feller, G.: Activity-stability relationships in extremophilic enzymes. J. Biol. Chem., 278, 7891-7896 (2003).

65. Collins, T., Meuwis, M. A., Gerday, C., and Feller, G.: Activity, stability and flexibility in glycosidases adapted to extreme thermal environments. J. Mol. Biol., 328, 419-428 (2003).

66. Cavicchioli, R., Siddiqui, K. S., Andrews, D., and Sowers, K. R.: Low-temperature extremophiles and their applications. Curr. Opin. Biotechnol., 13, 253-261 (2002).

67. Xu, Y., Feller, G., Gerday, C., and Glansdorff, N.: Metabolic enzymes from psychrophilic bacteria: challenge of adaptation to low temperatures in ornithine carbamoyltransferase from Moritella abyssi. J. Bacteriol., 185, 2161-2168 (2003).

68. Coker, J. A., Sheridan, P. P., Loveland-Curtze, J., Gutshall, K. R., Auman, A. J., and Brenchley, J. E.: Biochemical characterization of a $\beta$-galactosidase with a low temperature optimum obtained from an Antarctic arthrobacter isolate. J. Bacteriol., 185, 5473-5482 (2003).

69. Kumar, S., Tsai, C. J., and Nussinov, R.: Maximal stabilities of reversible two-state proteins. Biochemistry, 41, 53595374 (2002).

70. Feller, G., d'Amico, D., and Gerday, C.: Thermodynamic stability of a cold-active $\alpha$-amylase from the Antarctic bacterium Alteromonas haloplanctis. Biochemistry, 38, 46134619 (1999).

71. Becktel, W. J. and Schellman, J. A.: Protein stability curves. Biopolymers, 26, 1859-1877 (1987).

72. Makhatadze, G. I. and Privalov, P. L.: Energetics of protein structure. Adv. Protein Chem., 47, 307-425 (1995).

73. Tsai, C. J., Ma, B., and Nussinov, R.: Folding and binding cascades: shifts in energy landscapes. Proc. Natl. Acad. Sci. USA, 96, 9970-9972 (1999).

74. Kumar, S., Ma, B., Tsai, C. J., Sinha, N., and Nussinov, R.: Folding and binding cascades: dynamic landscapes and population shifts. Protein Sci., 9, 10-19 (2000).

75. Ma, B., Kumar, S., Tsai, C. J., and Nussinov, R.: Folding funnels and binding mechanisms. Protein Eng., 12, 713-720 (1999).

76. Wintrode, P. L. and Arnold, F. H.: Temperature adaptation of enzymes: lessons from laboratory evolution. Adv. Protein Chem., 55, 161-225 (2000).

77. Cherry, J. R., Lamsa, M. H., Schneider, P., Vind, J., Svendsen, A., Jones, A., and Pedersen, A. H.: Directed evolution of a fungal peroxidase. Nat. Biotechnol., 17, 379384 (1999).

78. Giver, L., Gershenson, A., Freskgard, P. O., and Arnold, F. H.: Directed evolution of a thermostable esterase. Proc. Natl. Acad. Sci. USA, 95, 12809-12813 (1998).

79. Miyazaki, K., Wintrode, P. L., Grayling, R. A., Rubingh, D. N., and Arnold, F. H.: Directed evolution study of temperature adaptation in a psychrophilic enzyme. J. Mol. Biol., 297, 1015-1026 (2000)

80. Roovers, M., Sanchez, R., Legrain, C., and Glansdorff, N.: Experimental evolution of enzyme temperature activity profile: selection in vivo and characterization of low-temperature-adapted mutants of Pyrococcus furiosus ornithine carbamoyltransferase. J. Bacteriol., 183, 1101-1105 (2001).

81. Taguchi, S., Ozaki, A., and Momose, H.: Engineering of a cold-adapted protease by sequential random mutagenesis and a screening system. Appl. Environ. Microbiol., 64, 492 495 (1998)

82. Lebbink, J. H., Kaper, T., Bron, P., van der Oost, J., and de Vos, W. M.: Improving low-temperature catalysis in the hyperthermostable Pyrococcus furiosus $\beta$-glucosidase CelB by directed evolution. Biochemistry, 39, 3656-3665 (2000).

83. Merz, A., Yee, M. C., Szadkowski, H., Pappenberger, G., Crameri, A., Stemmer, W. P., Yanofsky, C., and Kirschner,
K.: Improving the catalytic activity of a thermophilic enzyme at low temperatures. Biochemistry, 39, 880-889 (2000).

84. Yasugi, M., Amino, M., Suzuki, T., Oshima, T., and Yamagishi, A.: Cold adaptation of the thermophilic enzyme 3-isopropylmalate dehydrogenase. J. Biochem. (Tokyo), 129, 477-484 (2001).

85. Lonn, A., Gardonyi, M., van Zyl, W., Hahn-Hagerdal, B., and Otero, R. C.: Cold adaptation of xylose isomerase from Thermus thermophilus through random PCR mutagenesis. Gene cloning and protein characterization. Eur. J. Biochem., 269, 157-163 (2002).

86. Sterner, R., Kleemann, G. R., Szadkowski, H., Lustig, A., Hennig, M., and Kirschner, K.: Phosphoribosyl anthranilate isomerase from Thermotoga maritima is an extremely stable and active homodimer. Protein Sci., 5, 2000-2008 (1996).

87. Fields, P. A.: Protein function at thermal extremes: balancing stability and flexibility. Comp. Biochem. Physiol. A Mol. Integr. Physiol., 129, 417-431 (2001).

88. Hochachka, P. W. and Somero, G. N.: Temperature adaptation, p. 355-449. In Hochacka, P. W. and Somero, G. N. (ed.), Biochemical adaptations. Princeton University Press, Princeton (1984).

89. Tehei, M., Franzetti, B., Madern, D., Ginzburg, M., Ginzburg, B. Z., Giudici-Orticoni, M. T., Bruschi, M., and Zaccai, G.: Adaptation to extreme environments: macromolecular dynamics in bacteria compared in vivo by neutron scattering. EMBO Rep., 5, 66-70 (2004).

90. Zaccai, G.: How soft is a protein? A protein dynamics force constant measured by neutron scattering. Science, 288, 16041607 (2000).

91. Kohen, A., Cannio, R., Bartolucci, S., and Klinman, J. P.: Enzyme dynamics and hydrogen tunnelling in a thermophilic alcohol dehydrogenase. Nature, 399, 496-499 (1999).

92. Zavodszky, P., Kardos, J., Svingor, A., and Petsko, G. A.: Adjustment of conformational flexibility is a key event in the thermal adaptation of proteins. Proc. Natl. Acad. Sci. USA, 95, 7406-7411 (1998).

93. Wrba, A., Schweiger, A., Schultes, V., Jaenicke, R., and Zavodsky, P.: Extremely thermostable D-glyceraldehyde3-phosphate dehydrogenase from the eubacterium Thermotoga maritima. Biochemistry, 29, 7584-7592 (1990)

94. Svingor, A., Kardos, J., Hajdu, I., Nemeth, A., and Zavodszky, P.: A better enzyme to cope with cold comparative flexibility studies on psychrotrophic, mesophilic, and thermophilic ipmdhs. J. Biol. Chem., 276, 28121-28125 (2001)

95. Fitter, J., Herrmann, R., Dencher, N. A., Blume, A., and Hauss, T.: Activity and stability of a thermostable $\alpha$-amylase compared to its mesophilic homologue: mechanisms of thermal adaptation. Biochemistry, 40, 10723-10731 (2001).

96. Ichikawa, J. K. and Clarke, S.: A highly active protein repair enzyme from an extreme thermophile: the L-isoaspartyl methyltransferase from Thermotoga maritima. Arch. Biochem. Biophys., 358, 222-231 (1998).

97. Merz, A., Knochel, T., Jansonius, J. N., and Kirschner, K.: The hyperthermostable indoleglycerol phosphate synthase from Thermotoga maritima is destabilized by mutational disruption of two solvent-exposed salt bridges. J. Mol. Biol., 288, 753-763 (1999).

98. Aguilar, C. F., Sanderson, I., Moracci, M., Ciaramella, M., Nucci, R., Rossi, M., and Pearl, L. H.: Crystal structure of the $\beta$-glycosidase from the hyperthermophilic archeon Sulfolobus solfataricus: resilience as a key factor in thermostability. J. Mol. Biol., 271, 789-802 (1997).

99. Jaenicke, R.: Do ultrastable proteins from hyperthermophiles have high or low conformational rigidity? Proc. Natl. Acad. Sci. USA, 97, 2962-2964 (2000).

100. Tehei, M., Madern, D., Pfister, $\mathbf{C}$, and Zaccai, G.: Fast 
dynamics of halophilic malate dehydrogenase and BSA measured by neutron scattering under various solvent conditions influencing protein stability. Proc. Natl. Acad. Sci. USA, 98, 14356-14361 (2001).

101. Hernandez, G., Jenney, F. E., Jr., Adams, M. W., and LeMaster, D. M.: Millisecond time scale conformational flexibility in a hyperthermophile protein at ambient temperature. Proc. Natl. Acad. Sci. USA, 97, 3166-3170 (2000).

102. Margesin, R., Feller, G., Gerday, C., and Russell, N.: Cold-adapted microorganisms: adaptation strategies and biotechnological potential, p. 871-885. In Bitton, G. (ed.), The encyclopedia of environmental microbiology. John Wiley \& Sons, New York (2002).

103. Feller, G., Le Bussy, O., and Gerday, C.: Expression of psychrophilic genes in mesophilic hosts: assessment of the folding state of a recombinant $\alpha$-amylase. Appl. Environ.
Microbiol., 64, 1163-1165 (1998).

104. Tutino, M. L., Duilio, A., Parrilli, R., Remaut, E., Sannia, G., and Marino, G.: A novel replication element from an Antarctic plasmid as a tool for the expression of proteins at low temperature. Extremophiles, 5, 257-264 (2001).

105. Gerday, C., Aittaleb, M., Bentahir, M., Chessa, J. P., Claverie, P., Collins, T., D'Amico, S., Dumont, J., Garsoux, G., Georlette, D., and 4 other authors: Cold-adapted enzymes: from fundamentals to biotechnology. Trends Biotechnol., 18, 103-107 (2000).

106. Feller, G., Lonhienne, T., Deroanne, C., Libioulle, C., Van Beeumen, J., and Gerday, C.: Purification, characterization, and nucleotide sequence of the thermolabile $\alpha$-amylase from the antarctic psychrotroph Alteromonas haloplanctis A23. J. Biol. Chem., 267, 5217-5221 (1992). 